\title{
Reformulating Minas Frescal cheese using consumers' perceptions: Insights from intensity scales and check-all-that-apply questionnaires
}

\author{
E. W. Oliveira, ${ }^{*}$ E. A. Esmerino, ${ }^{*} \dagger$ B. Thomas Carr,‡ L. P. F. Pinto, ${ }^{*}$ H. L. A. Silva, ${ }^{*}$ T. C. Pimentel, $\S$ \\ H. M. A. Bolini, $†$ A. G. Cruz, \# $\#^{1}$ and M. Q. Freitas* \\ *Universidade Federal Fluminense, Faculdade de Medicina Veterinária, 24230-340 Niterói, Rio de Janeiro, Brazil \\ †Universidade Estadual de Campinas, Faculdade de Engenharia de Alimentos, Cidade Universitária Zeferino Vaz, 13083-862 Campinas, \\ São Paulo, Brazil \\ ‡Carr Consulting, 1215 Washington Avenue, Suite 203, Wilmette, IL 60091 \\ §Instituto Federal do Paraná, Paranavaí, 87703-536, Paraná, Brazil \\ \#Instituto Federal de Educação, Ciência e Tecnologia do Rio de Janeiro, Departamento de Alimentos, 20270-021, Rio de Janeiro, Brazil
}

\begin{abstract}
We evaluated the performance of check-all-that-apply (CATA) questions and intensity scales to describe Minas Frescal cheese and its reformulation based on consumers' perceptions. Ten commercial samples with different formulations (full-fat, low-fat, or low-lactose) were evaluated by 200 consumers divided equally into 2 groups: 1 evaluated samples and described their ideal cheese using intensity scales and 1 did the same using CATA questions. Both methodologies provided similar information about the sensory characteristics of the Minas Frescal cheeses, the description of the ideal product, and directions for product reformulation. The ideal Minas Frescal cheese was characterized by high moisture, intense white color, homogeneous mass, typical Minas Frescal cheese aroma and flavor, softness, and juiciness. For the intensity scales, the recommendation was to increase the typical aroma and flavor, salty taste, and juiciness, and to decrease the bitter flavor; for the CATA questions, only increasing the typical Minas Frescal cheese flavor was important for all classes of cheeses. Even for a heterogeneous product with no defined manufacturing protocol, both methodologies presented satisfactory results that should be considered for use by cheese producers and the dairy industry.
\end{abstract}

Key words: check-all-that-apply (CATA) questions, intensity scales, Minas Frescal cheese, product reformulation

\section{INTRODUCTION}

Sensory analysis techniques are important tools for product improvement. In the food industry, a key step

\footnotetext{
Received November 19, 2016

Accepted April 7, 2017.

${ }^{1}$ Corresponding author: food@globo.com
}

in developing and reformulating food products is the selection of a final formulation that is in agreement with consumer preferences (Van Kleef et al., 2006; Bruzzone et al., 2015). For this reason, using consumer opinions to obtain a sensory description of the products and hedonic judgments allows manufacturers to identify the sensory characteristics of the ideal product and develop recommendations for its reformulation (Moskowitz and Hartmann, 2008; Ares et al., 2017).

Intensity scales are recommended for product optimization because they have little influence on overall consumer preference (Moskowitz, 2001; Popper et al., 2004), and they consider the consumer's ability to assess the intensity of sensory attributes (Moskowitz, 1996; Husson, Le Dien and Pagès, 2001; Worch et al., 2010), given a previous and implicit understanding of the ideal product. However, using intensity scales to describe a large set of attributes can be tedious for consumers, and it can result in high variability in the use of the scales and low discrimination among the samples (Ares et al., 2011a; Bruzzone et al., 2015).

Check-all-that-apply (CATA) questions are one of the rapid approaches that have recently been introduced in sensory analysis (Meyners et al., 2013); they are easy to implement and not tedious for consumers (Ares et al., 2014; Jaeger and Ares, 2014; Jaeger et al., 2013). Previous studies have shown that sensory characterization performed by trained assessors and by consumers using CATA questions provided very similar results (Ares et al., 2010; Dooley et al., 2010; Bruzzone et al., 2012; Antunes et al., 2017). Furthermore, the use of CATA questions to identify the sensory characteristics of the ideal product (Cowden et al., 2009; Ares et al., 2011b), associated with a penalty analysis approach, allows researchers to determine how much the overall liking is reduced by deviations in sensory profiles between real and ideal products (Plaehn, 2012).

Among typical Brazilian dairy foods, Minas Frescal cheese is important due to its high yield, relatively low 
production cost, and easy manufacturing process (Dantas et al., 2016). Minas Frescal cheese has a shortened shelf life because of its high moisture content and low salt content, so it is consumed fresh. The absence of a defined manufacturing protocol may enable physicochemical and sensory changes during storage, sometimes making it unacceptable for consumers.

Studies of the sensory profile and commercial acceptance of Minas Frescal cheese, as well as descriptive methods performed by trained assessors, are scarce (Afonso et al., 2002). It is essential to understand the sensory characteristics of Minas Frescal cheese from a consumer perspective to signal consumer preferences with respect to the intrinsic attributes of Minas Frescal cheese, making it possible to improve its sensory quality.

The present study compared the performance of intensity scales and CATA questions about the reformulation of Minas Frescal cheese from a consumer's perspective. Both methodologies were evaluated in relation to their similarity, their sensory map of the products, and their description of the ideal product. Finally, recommendations for the reformulation of the products were also provided.

\section{MATERIALS AND METHODS}

\section{Samples}

Ten commercial brands of Minas Frescal cheese with different formulations (full-fat, low-fat, or low-lactose) were purchased in supermarkets in the city of Niterói, Rio de Janiero, Brazil, in their original packaging. All samples contained the Federal Inspection Service seal, allowing commercialization throughout the Brazil territory. The full-fat (FF) samples were coded as FF1, FF2, FF3, FF4, and FF5, the low-fat (LF) samples as LF1, LF2, LF3, and LF4, and the low-lactose (LL) sample as LL1.

Samples were presented to the consumers in a randomized and balanced order for both descriptive tests, according to MacFie et al. (1989). Prior to the sensory evaluation, consumers completed and signed a consent form to participate in the tests, and received a gift for their participation.

\section{Selection of the Sensory Descriptors}

Only 1 descriptive study with Minas Frescal cheese has been published (Afonso et al., 2002), and data on sensory characteristics of this product are almost nonexistent. Therefore, to elicit sensory descriptors for Minas Frescal cheese, Kelly's repertory grid method was applied (Moskowitz, 1983). A preliminary session was performed with 50 heavy users (12 men and 38 women, aged 21 to $38 \mathrm{yr}$ ), evaluating 2 samples of commercial Minas Frescal cheese. The consumers were asked to describe the similarities and differences between the samples in relation to appearance, aroma, flavor, and texture. Then, a discussion with all the consumers was conducted with the aim of selecting the vocabulary that covered the entire sensory profile of samples and could be used by each consumer to describe the differences between samples, generating a consensual descriptive list. The following terms, totaling 22 sensory descriptors, were selected: moisture, white color, yellow color, homogeneous mass; milk aroma, butter aroma, salty aroma, acid aroma, sweet aroma, typical Minas Frescal cheese aroma; milk flavor, butter flavor, typical Minas Frescal cheese flavor, bitter taste, salty taste, acid taste, sweet taste; softness, consistency, elasticity, fragmented texture, and juiciness.

\section{Consumer Study}

We recruited 200 consumers, different from those employed in the initial step, above, were recruited randomly and divided in 2 groups. The first group comprised 100 people (64 women and 36 men, ages 15 to $63 \mathrm{yr}$ ) and evaluated the samples using intensity scales. The second group also comprised 100 people, distinct from the first group (38 women and 62 men, aged 18 to $52 \mathrm{yr}$ ), and evaluated the samples using the CATA questionnaire. Consumers were recruited from Federal Fluminense University students, staff, and visitors, through emails, posters, and invitations via social networks.

All the consumers ate Minas Frescal cheese at least 2 times a week. At each evaluation, approximately 10 $\mathrm{g}$ of each sample was served to the consumers in 50$\mathrm{mL}$ white plastic cups, identified with 3 -digit random numbers. The samples were kept in a refrigerator at $9 \pm 1^{\circ} \mathrm{C}$ until the evaluation. The presentation was performed in a monadic and balanced order, in accordance with the methodology described by MacFie et al. (1989) and Kwak and Lee (2016). Panelists could take a break when they needed to, but no one took it or reported fatigue. During all the tests, mineral water and unsalted crackers were available for palate cleansing between samples.

\section{Intensity Scales}

Consumers evaluated the Minas Frescal cheese samples and were asked to mark the option that best suited the product in relation to overall acceptance us- 
ing a 9-point unstructured hedonic scale (Esmerino et al., 2015). Then, they were invited to designate the intensity of the sensory characteristics of the samples using a $10 \mathrm{~cm}$ unstructured linear scale, anchored with the term "low/none" on the left and "high" on the right. Definitions of the 22 descriptors were not provided; consumers evaluated them according to their understanding. After evaluating the sensory characteristics of each sample, consumers were invited to rate the desirable characteristics for an ideal Minas Frescal cheese using the same $10 \mathrm{~cm}$ unstructured linear scales (Worch et al., 2013; Bruzzone et al., 2015; Worch and Punter, 2015).

\section{CATA Questions}

Consumers were asked to rate the option that best suited the product in relation to overall acceptance, using a 9-point unstructured hedonic scale $(1=$ dislike extremely to $9=$ like extremely). Then, they received the CATA questionnaire with a list of sensory descriptors, and they were asked to select all terms that applied to describe the sensory characteristics of the sample (Ares et al., 2011a). The position of the descriptors was arranged in a balanced way according methodological recommendations (Ares et al., 2014). After evaluating all samples, consumers were asked to respond to a similar CATA questionnaire, marking the terms they considered important to describe the ideal Minas Frescal cheese, as suggested by Bruzzone et al. (2015).

\section{Data Analysis}

Acceptance Test. Overall acceptance data were analyzed using ANOVA, considering the sample as a fixed source of variation and the consumer as a random effect, at a significance level of $5 \%$. When means were found to be significant, differences were calculated using Tukey's test.

Intensity Scales. Intensity scales data were analyzed using ANOVA, considering the sample as a fixed source of variation and the consumer as a random effect, at a significance level of $P \leq 0.05$ and using Tukey's test. The data were also submitted to principal component analysis, using a correlation matrix to obtain the sensory map of the samples. Only descriptors that significantly discriminated the samples $(P \leq$ $0.05)$ were included in this analysis. In each axis, the descriptors that presented a correlation coefficient with a component higher than 0.7 (absolute values) were considered important (Marchi et al., 2012). The ideal product was considered as a supplementary sample.
Penalty analysis was carried out on consumer responses to determine the drop-in acceptability associated with deviations in sensory profiles between evaluated and ideal products, as detected by the intensity scales (Tarrega et al., 2016). For this, 2 dummy variables $(\mathrm{Z}+$ and $\mathrm{Z}-$ ) were created using the difference between perceived and ideal intensities for each product and each sensory descriptor (Bruzzone et al., 2015; Worch et al., 2010). The result was assigned to $\mathrm{Z}+$ when the difference was positive and to $\mathrm{Z}$ - when it was negative. In each case, the other binary variable was defined as $0(\mathrm{Z}$ - when the difference was positive and $\mathrm{Z}+$ when the difference was negative). Partial least squares (PLS) regression was used in both methodologies to study the relative influence of attributes on consumer liking and estimate how much the descriptors of the evaluated products deviated from the ideal product (Xiong and Meullenet, 2006). Overall acceptance scores were dependent variables and dummy variables were regressors (Bruzzone et al., 2015).

$\boldsymbol{C A T A}$. In CATA questions, the frequency of use of each sensory descriptor was determined by counting the number of consumers who used that term to describe each sample. To identify a significant difference between the samples for each term used in the CATA questions, we used Cochran's Q test (Meyners et al., 2013). Correspondence analysis was performed to obtain a bidimensional representation of the relationship between samples and descriptors (Santos et al., 2015). This analysis was performed on a frequency table containing the samples in rows and the descriptors in columns. To visualize the spatial location and correlation between the sample and the attributes, the ideal product was considered as a supplementary sample.

Penalty analysis was carried out on consumer responses to identify how much overall liking was reduced because of deviations in sensory profiles between real and ideal products, as detected by a CATA question (Ares et al., 2014). For this, 2 dummy variables ( $\mathrm{Z}+$ and Z-) were created (Meyners et al., 2013). If an attribute was used to describe the sample but not the ideal product, 0 was assigned to $\mathrm{Z}+$ and 1 to $\mathrm{Z}-$. If an attribute was used to describe the ideal product but not the sample, 1 was assigned to $\mathrm{Z}+$ and 0 to $\mathrm{Z}-$. When an attribute was used to describe the sample and the ideal product, it was assigned 0 for both dummy variables. In addition, the percentage of consumers who used each attribute to describe each sample and the ideal product was determined. We used PLS regression in both methodologies to estimate how much the descriptors of the evaluated products deviated from the ideal product. Overall acceptance scores were dependent variables and dummy variables were regressors (Bruzzone et al., 2015). 
Similarity Between Sensory Configurations. The similarity between the sensory profiling was obtained using multiple factor analysis using the configuration of the samples in the first 2 dimensions of the principal component analysis and correspondence analysis, for intensity scales and CATA questions, respectively. The RV coefficient (Robert and Escoufier, 1976) was used with measure of similarity of the methodologies. All statistical analyses were performed using XLSTAT version 2015.5 (Addinsoft, Paris, France).

Hierarchical Cluster Analysis. Hierarchical cluster analysis, considering Euclidean distances (dissimilarity) and the Ward aggregation criterion (agglomeration method), was performed for both methodologies to identify groups of samples with different sensory characteristics in the bidimensional map using the coordinates of the first 2 components of the principal component analysis and the correspondence analysis, respectively, for each method. This approach has been used with success in previous studies to evaluate and determine similarities and differences among sensory methods (Albert et al., 2011; Ares et al., 2013; Cruz et al., 2013).

\section{RESULTS AND DISCUSSION}

Significant differences were found in overall acceptance among all samples $(P \leq 0.05$; Table 1$)$. In both methodologies, scores above 6 ("I liked it slightly") were verified for FF1, FF2, FF3, FF4, FF5, LF1, and LF4 samples. We also found little disagreement about the LL1 sample, which received a score of 5.4 in the intensity scales and 6.8 in the CATA questions. The LF2 and LF3 samples, both low-fat products, were the least preferred; they presented the lowest means $(P<0.05)$ in overall acceptance, probably due to their accentuated bitter taste and consistency identified in both tests, and to their acid and sweet aromas and tastes, identified in the intensity scales and CATA questions, respectively. According to the intensity scales, the most preferred samples were FF2, FF5, LF1, and LF4; according to theCATA questions, the most preferred samples were FF1, FF5, LL1, and LF4 $(P<0.05)$.

Table 2 shows the intensity of the sensory descriptors of Minas Frescal cheese samples evaluated by consumers using intensity scales. We found highly significant differences $(P<0.001)$ among the samples for 16 of the 22 attributes. The consumers did not detect differences between the samples for homogeneous mass, milk aroma, butter aroma, sweet aroma, sweet flavor, or fragmented texture $(P>0.05)$, suggesting that reduction in fat or lactose content would not influence these descriptors significantly .
The first 2 dimensions of the principal component analysis accounted for $77.68 \%$ of the variance in the experimental data, at $57.84 \%$ and $19.84 \%$ in the first and second dimensions, respectively (Figure 1). Based on these findings, the samples presented different sensory profiles.

As shown in Figure 2A, the dendrogram generated by hierarchical cluster analysis divided the samples into 3 groups: Group 1 consisted of FF1, FF2, FF3, FF4, FF5, LF1, and LF4; Group 2 consisted of LF2, LL1, and LF3; and Group 3 consisted of the ideal product. Full-fat samples (FF1, FF2, and FF4) were characterized by the intensity of their yellow color. The low-fat sample LF4 and the full-fat sample FF5 were moist and had a greater intensity of milk flavor, butter flavor, softness, juiciness, salty flavor, and typical Minas Frescal aroma and flavor. The low-fat sample LF2 and the low-lactose sample LL1 were mainly characterized by their consistency. The LF3 sample was mainly characterized by its bitter taste and acid aroma and taste. Samples FF3 and LF1 represented intermediate intensities of the descriptors.

The Cochran's Q test of the CATA findings indicated no significant difference between the samples for yellow color and fragmented texture (Table 3). However, the consumers could verify differences between the samples for the other 20 attributes, showing the consumers' discriminatory capacity. The sensory descriptors moisture, white color, homogeneous mass, and softness were chosen more often when consumers were asked to describe the sensory characteristics of Minas Frescal cheeses. These terms showed an average frequency of use of more than $40 \%$.

Table 1. Overall acceptance scores for Minas Frescal cheese samples using intensity scales and check-all-that-apply (CATA) questions ${ }^{1}$ (means with SD in parentheses)

\begin{tabular}{lcl}
\hline Sample $^{2}$ & Intensity scale & CATA \\
\hline FF1 & $6.4(1.6)^{\mathrm{bcd}}$ & $6.7(1.8)^{\mathrm{ab}}$ \\
FF2 & $6.8(1.5)^{\mathrm{abc}}$ & $6.5(1.5)^{\mathrm{bc}}$ \\
FF3 & $6.0(1.7)^{\mathrm{de}}$ & $6.4(1.6)^{\mathrm{bc}}$ \\
FF4 & $6.1(1.7)^{\mathrm{cde}}$ & $6.3(1.7)^{\mathrm{bc}}$ \\
FF5 & $7.3(1.6)^{\mathrm{a}}$ & $7.4(1.4)^{\mathrm{a}}$ \\
LF1 & $6.6(1.5)^{\mathrm{abcd}}$ & $6.5(1.6)^{\mathrm{bc}}$ \\
LF2 & $4.6(2.3)^{\mathrm{f}}$ & $5.9(1.9)^{\mathrm{c}}$ \\
LF3 & $2.4(1.8)^{\mathrm{g}}$ & $3.6(1.9)^{\mathrm{d}}$ \\
LF4 & $7.0(1.6)^{\mathrm{ab}}$ & $7.0(1.7)^{\mathrm{ab}}$ \\
LL1 & $5.4(2.1)^{\mathrm{ef}}$ & $6.8(1.5)^{\mathrm{ab}}$
\end{tabular}

${ }^{\mathrm{a}-\mathrm{g}}$ Means with different superscript letters in the same column differed (Tukey's test; $P<0.05$ ).

${ }^{1} 1=$ dislike extremely; $9=$ like extremely.

${ }^{2} \mathrm{FF}=$ full-fat samples; LF = low-fat samples; LL = low-lactose sample. 


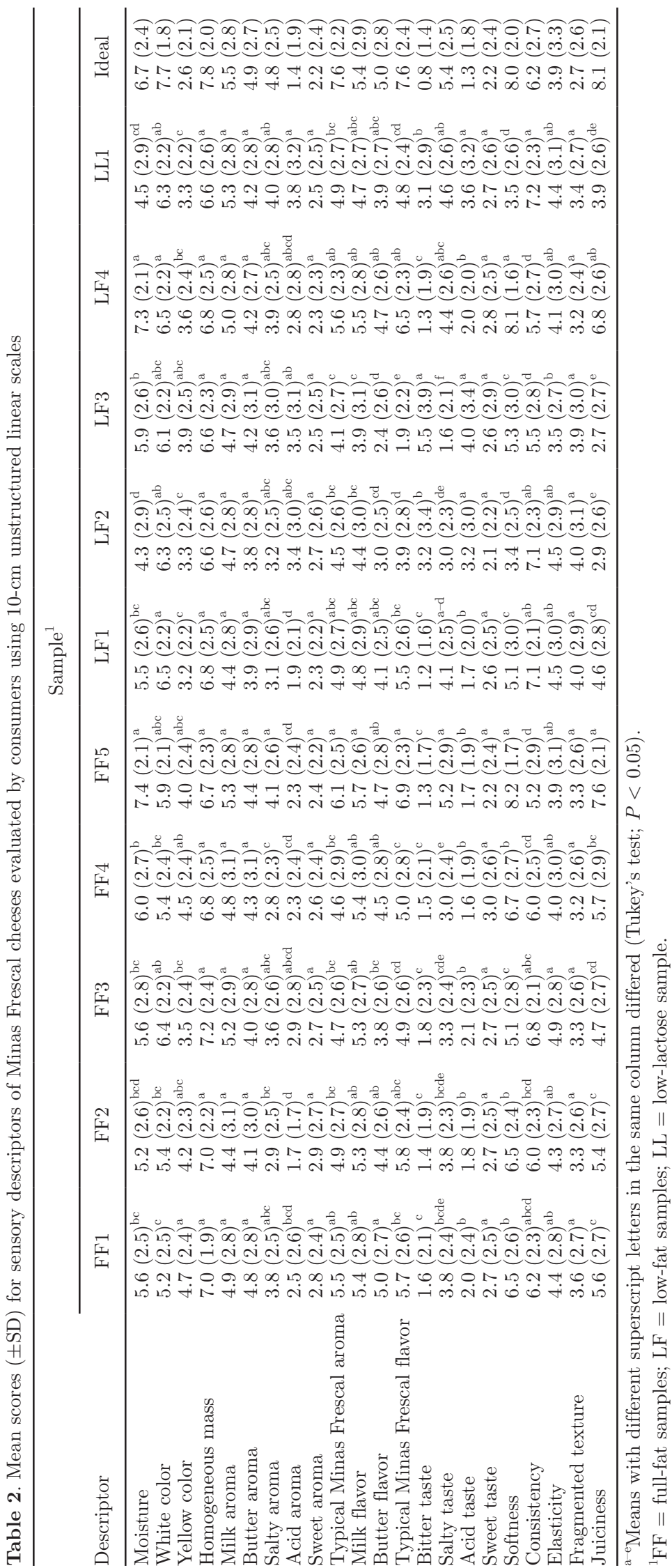


The correspondence analysis bidimensional map obtained using the CATA findings is shown in Figure 3. Approximately $80 \%$ of findings were obtained in 2 dimensions, 59.44 and $20.20 \%$ in the first and second dimensions, respectively. As shown in Figure 2B, the dendrogram obtained by hierarchical cluster analysis sorted the samples into 4 groups: Group 1 consisted of FF1, FF3, and FF4; Group 2 consisted of LF1, FF2, LF2, and LL1; Group 3 consisted of LF3; and Group 4 consisted of FF5, LF4, and the ideal product. Samples LF4 and FF5 were characterized by their higher intensity of salty aroma and flavor, and their typical Minas Frescal flavor and juiciness. Samples FF1, FF3, and FF4 were more moist, soft, and homogeneous. The full-fat sample FF2, low-fat samples LF1 and LF2, and low-lactose sample LL1 were characterized by their milk aroma and flavor, consistency, fragmented texture, sweet flavor, and elasticity. The LF3 sample was considered different from the others and had a higher intensity of sweet aroma and bitter taste, similar to what was found in the other analysis.

We tested the RV coefficient value between the sample configurations from the 2 methodologies. The value of RV varies between 0 and 1 ; the closer to 1 , the better the correlation between the tested (intensity scales and CATA questions; Santos et al., 2015). The coefficient value obtained $(\mathrm{RV}=0.767)$ was significant $(P=0.001)$, indicating that the methodologies could produce similar findings.

Considering mean values from the intensity scales (Table 2), the ideal Minas Frescal cheese had high moisture, intense white color, homogeneity, pronounced typical Minas Frescal aroma and flavor, softness, and juiciness. The CATA questions generated very similar information (Table 3): the ideal product had high moisture, white color, homogeneous mass, typical Minas Frescal aroma and flavor, salty flavor, softness, and juiciness. According to both methodologies, samples FF5

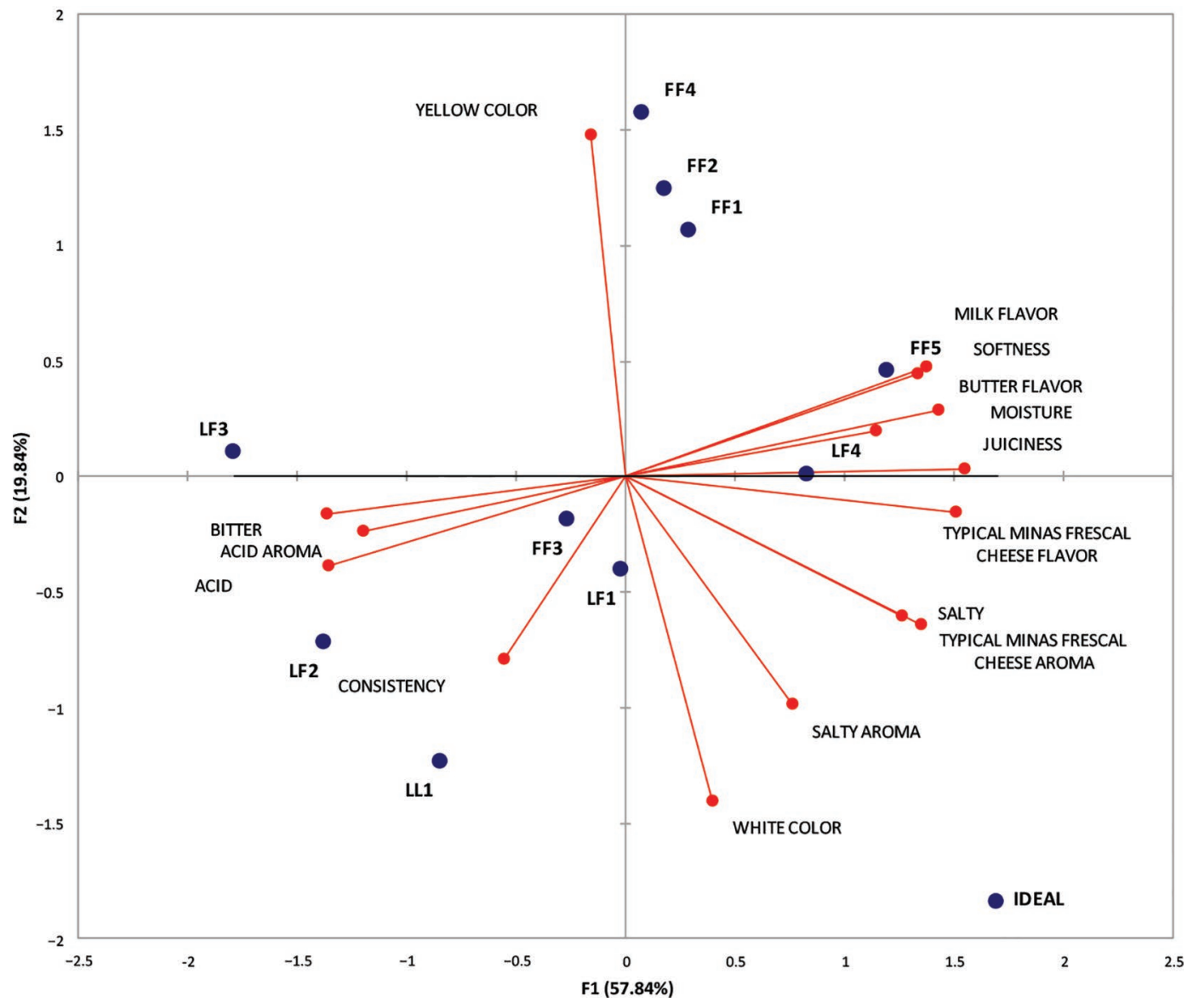

Figure 1. Representation of the samples, the ideal product, and the descriptors in the first and second dimensions of the principal component analysis of intensity scales values. FF $=$ full-fat samples; $\mathrm{LF}=$ low-fat samples; LL = low-lactose sample. The ideal product was considered as a supplementary sample. Color version available online. 
and LF4 were most similar to the ideal Minas Frescal cheese, in agreement with their high scores for overall acceptance (Table 1).

Table 4 presents the findings of the penalty analysis and PLS regression performed on the intensity scales data. The PLS model allowed us to identify devia-
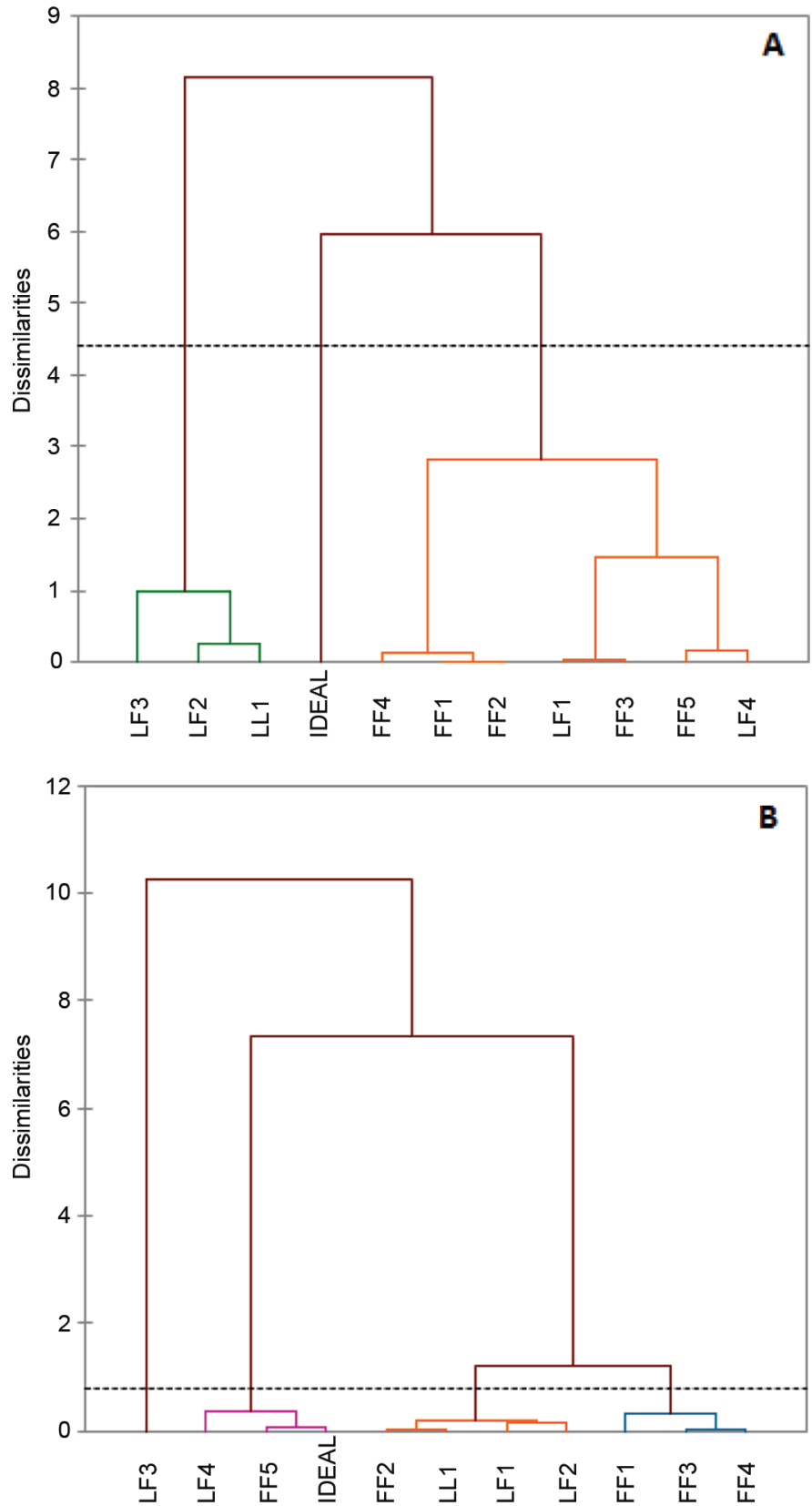

Figure 2. Representation of the dendrogram obtained from hierarchical cluster analysis of (A) intensity scales, and (B) check-all-thatapply (CATA) questions. FF = full-fat samples; $\mathrm{LF}=$ low-fat samples; $\mathrm{LL}=$ low-lactose sample. The dotted line represent the automatic truncation. Color version available online. tions from the ideal that affected overall acceptance. The maximum potential for increase in the overall acceptance score if attributes that deviated from the ideal were modified ranged from 0.6 to 2.4. This information directs the reformulation of Minas Frescal cheeses based on potential gain in overall acceptance scores. The dummy variables typical Minas Frescal flavor+ and typical Minas Frescal flavor- significantly affected the overall acceptance scores for all samples. By combining Table 4 with Table 2-which contains the mean intensities of the descriptors for the samples and the ideal Minas Frescal cheese - we were able to identify recommendations for improving each of the samples evaluated. In the case of typical Minas Frescal flavor, we inferred that the ideal for consumers would be a product with a greater intensity of this attribute. On the other hand, the dummy variables homogeneous mass + , homogeneous mass-, milk flavor+, and milk flavor - did not significantly affect overall acceptance in any sample, indicating that variation in the intensity of these attributes does not imply significant changes in overall acceptance by consumers.

Samples LF1, FF2, FF5, and LF4 obtained the highest scores for overall acceptance, with values of 6.6 , $6.8,7.3$, and 7 , respectively (Table 1 ). Because 3 types of cheese formulations were used (full-fat, low-fat and low-lactose), we decided to make recommendations by class using the most cited terms in each class, as presented in Table 5. Our recommendation was to increase the intensity of typical Minas Frescal aroma and flavor, salty taste, and juiciness, and reduce bitter taste for all classes, indicating that these descriptors were very important for an ideal Minas Frescal cheese product.

The results of the penalty analysis performed on CATA questions data are shown in Table 6. As suggested by Xiong and Meullenet (2006) and Plaehn (2012), all dummy variables were considered in the PLS regression, but only those indicated for at least $20 \%$ of consumers were considered to be relevant. The maximum potential for increase in the overall acceptance score if attributes that deviated from the ideal were modified ranged from 0.6 to 1.1. The variables yellow color + , yellow color - , salty aroma + , salty aroma-, butter aroma + and butter aroma- did not significantly affect overall acceptance for any sample, indicating that variation in their intensity did not interfere with the results of this analysis. Typical Minas Frescal flavor + , softness + , consistency + , and juiciness + significantly affected overall preference in at least 4 of the 10 samples evaluated. By combining the data from Table 6 with Table 3 -which contains the frequency of attribute citation for the samples evaluated and for the ideal Minas Frescal cheese - we were able to obtain 
OLIVEIRA ET AL.

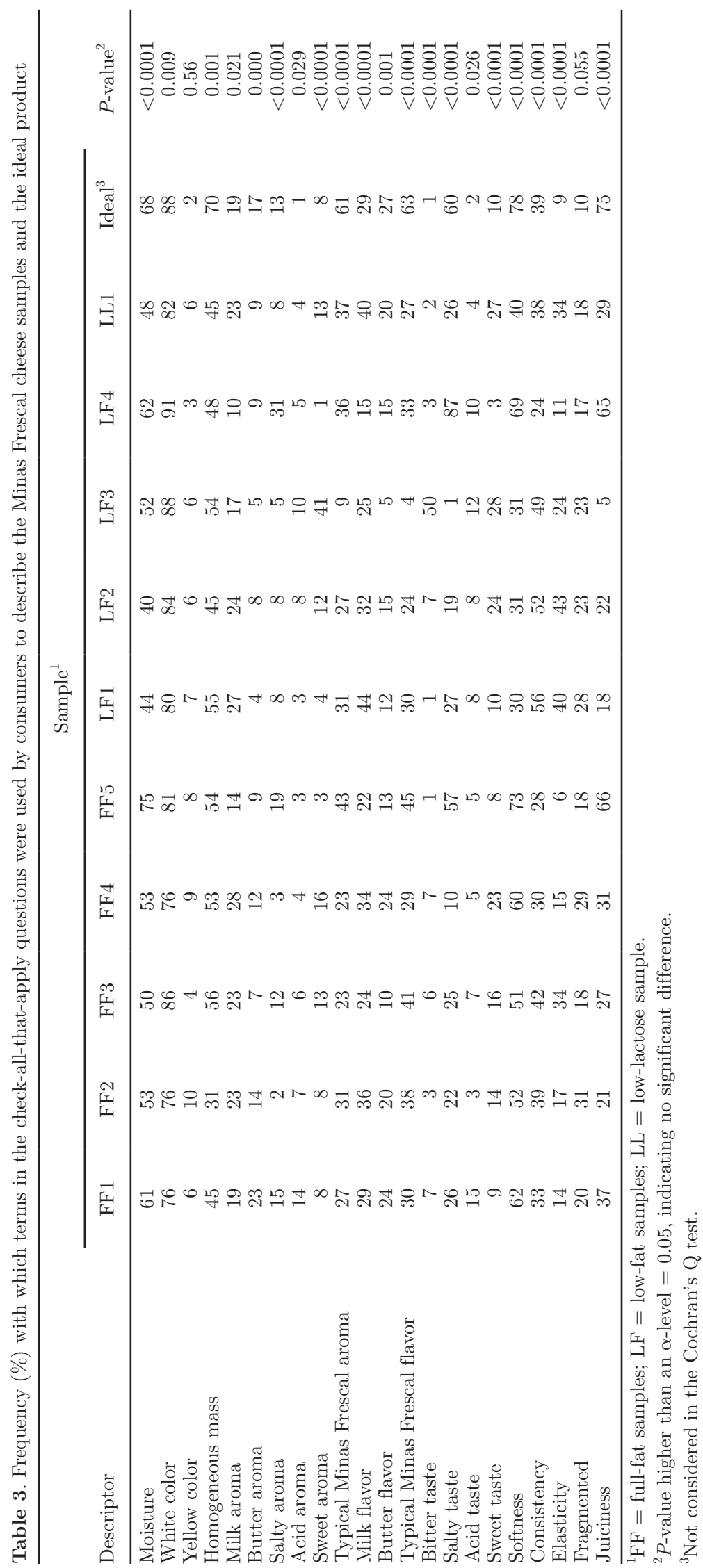


recommendations for improving each of the samples. In relation to the descriptors referenced above, an increase in the intensity of these descriptors would lead to a better overall acceptance score. Samples FF1, LL1, FF5, and LF4 had the highest overall acceptance scores, at $6.7,6.8,7.4$, and 7.0, respectively (Table 1 ).

Table 5 also presents recommendations by class for the CATA question methodology. In this case, only typical Minas Frescal flavor appeared in all classes, emphasizing the importance of its presence in an ideal Minas Frescal cheese. We found no influence of methodology in overall acceptance scores, because we performed the hedonic evaluation was performed before each method was applied, corroborating the studies of Jaeger and Ares (2014) and Jaeger et al. (2013), in which intensity scales and CATA questions did not influence hedonic scores.

Consumers were not able to identify significant differences for 6 descriptors using the intensity scales and for 2 attributes using the CATA questions, suggesting the superiority of CATA questions for discriminating between samples. These data corroborated the study of Ares et al. (2011a), who reported that the discriminative capacity of consumers on intensity scales was low.
Multiple factor analysis performed on the data from the intensity scales and CATA questions presented similar information, as evidenced by the RV coefficient. The results of the present study corroborate those of Bruzzone et al. (2015), which point out that although CATA questions do not allow for direct measurement of the sensory intensity of attributes, they may generate similar results to those obtained with the intensity scales. In agreement with Worch et al. (2012), who stated that the information about the ideal product can be considered consistent if its description is similar to products with the highest overall acceptance scores, the ideal product position on both sensory maps was close to the samples that had the highest overall acceptance scores (FF5 and LF4 samples).

The use of PLS regression in the penalty analysis provided specific models for Minas Frescal cheese, allowing us to determine the potential gain in overall acceptance scores and provided guidelines for reformulation of the product. In all penalty analyses, deviation from the ideal in typical Minas Frescal flavor descriptor significantly affected overall acceptance in almost all samples. According to the intensity scales, bitter taste significantly affected overall acceptance in 9 of the 10 samples.

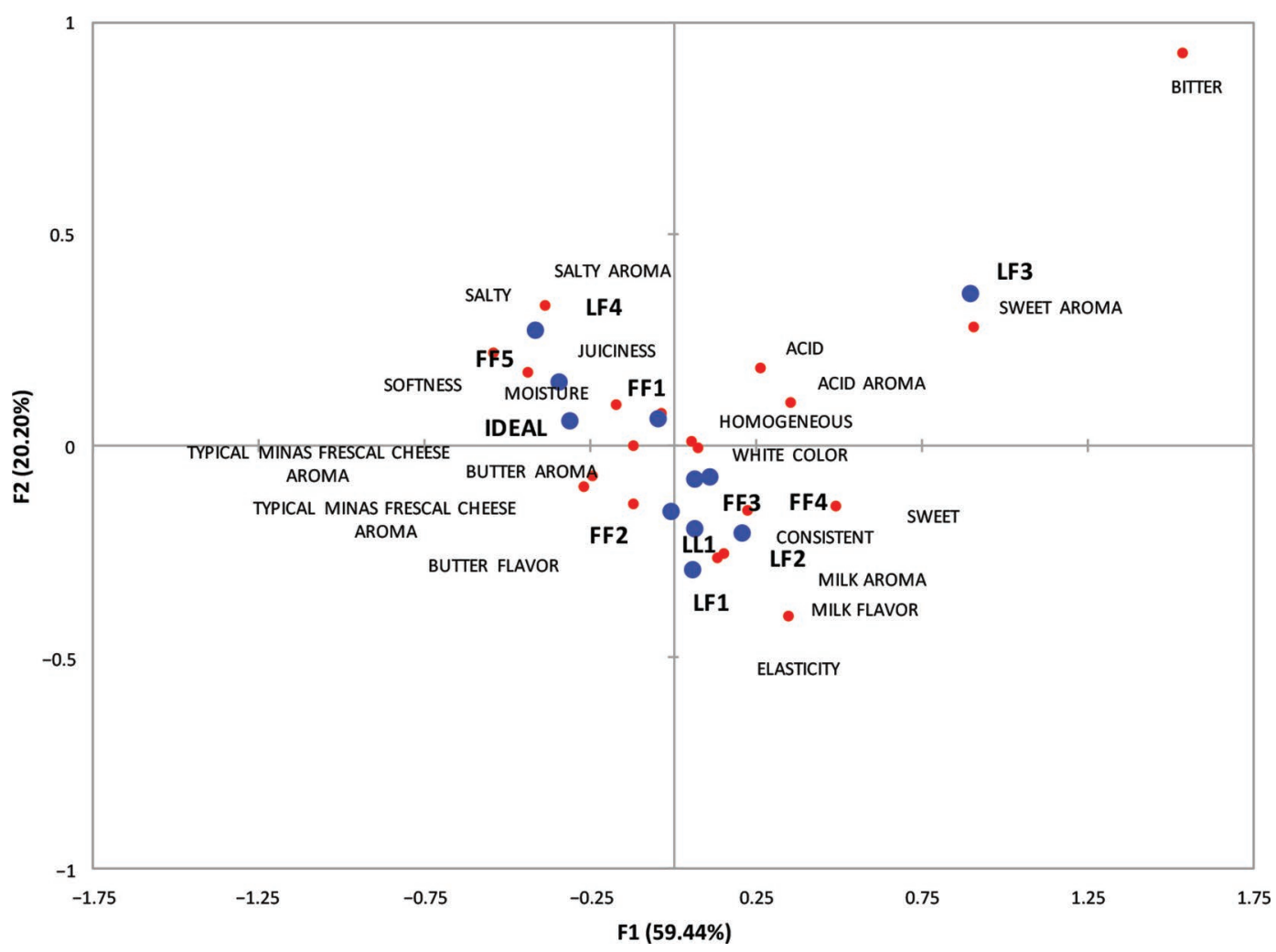

Figure 3. Representation of the samples, the ideal product, and the descriptors in the first and second dimensions of the correspondence analysis of the frequency table of check-all-that-apply questions. FF = full-fat samples; LF = low-fat samples; LL $=$ low-lactose sample. The ideal product was considered as a supplementary sample. Color version available online. 


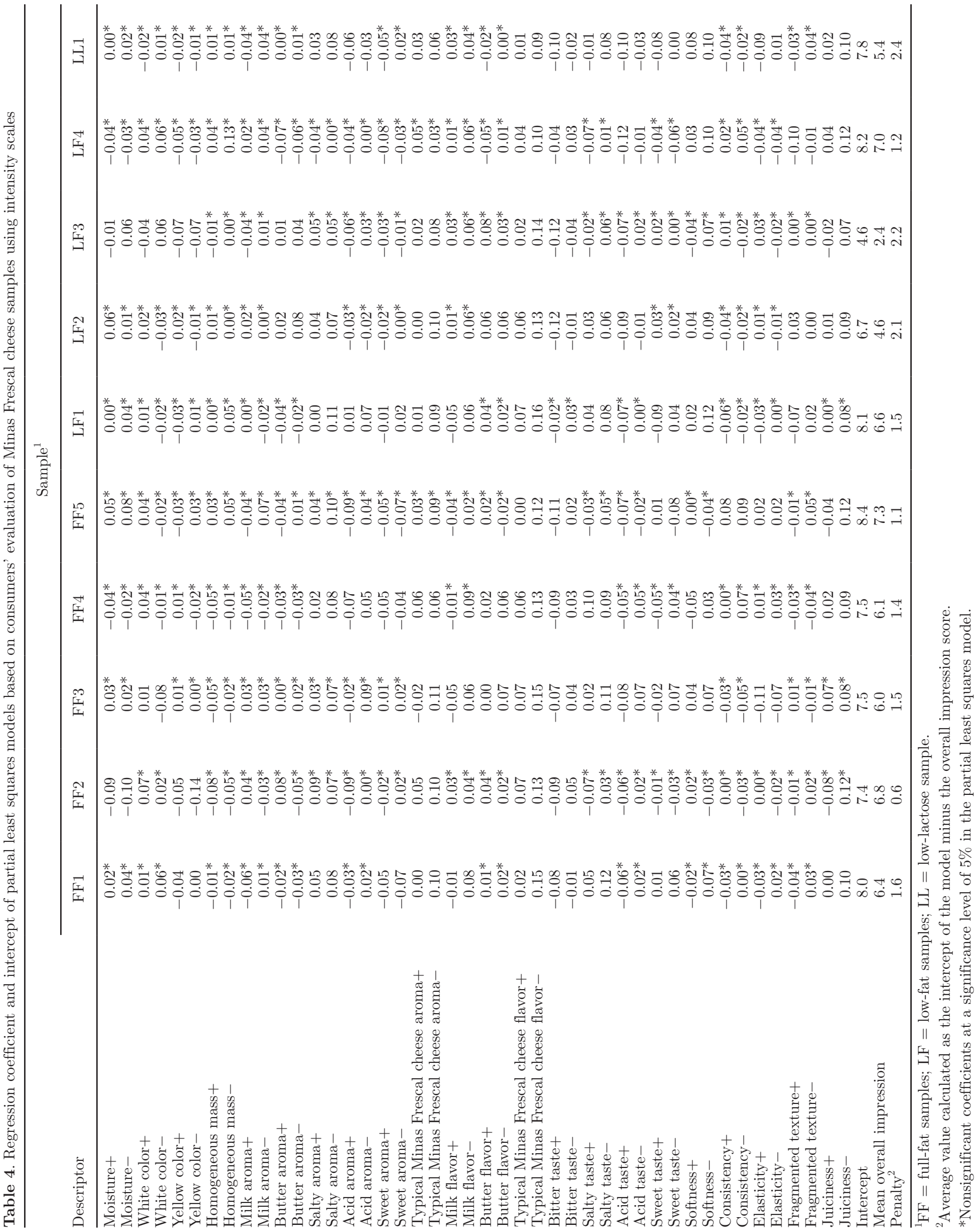


Table 5. Recommendations for changes in the samples, based on results from the partial least squares model for intensity scales and check-allthat-apply (CATA) questions

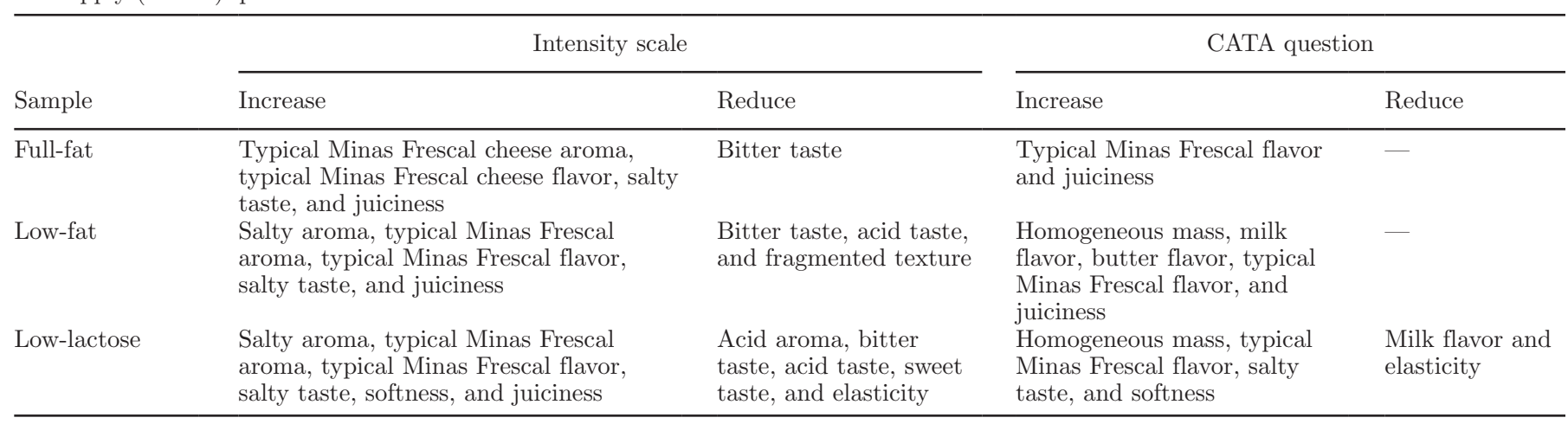

According to the intensity scales, the most cited descriptors for reformulation of Minas Frescal cheeses were typical Minas Frescal aroma and flavor, salty taste, softness, and juiciness, and according to the CATA questions, the most cited descriptors were typical Minas Frescal flavor, milk flavor, butter flavor, softness, homogeneous mass, and juiciness, indicating that the ideal product should have such characteristics.

Based on intensity scales, our recommendation was to reformulate products by increasing the intensity of the typical Minas Frescal cheese aroma and flavor, salty taste, and juiciness and to decrease bitter taste. Based on CATA questions, only an increase in intensity of the typical Minas Frescal cheese flavor was important for all classes of cheeses. For cheese improvement, the intensity of these attributes should be increased by modifying the formulation and the production process.

These results can be justified by the fact that Minas Frescal cheese is a very heterogeneous product, with diversity in its operational parameters, and manufactured by small, medium, and large dairy producers. It is interesting to observe that previous studies used products with total control of all factors related to the processing, with few influences on their sensory characteristics, such as dairy desserts and orange-flavored powdered beverages, and they showed similar results (Ares et al., 2011a; Bruzzone et al., 2015).

Other issues may have influenced differences in the present findings. First, the time spent by consumers to complete the tests may have influenced their responses; intensity scales took longer to complete (15 to $25 \mathrm{~min}$ ) than CATA questions (5 to $15 \mathrm{~min}$ ). As well, the length of the list of descriptors (22 sensory terms), may have contributed to lowering the number of descriptors used in the recommendations for product reformulations using the CATA questions compared with attributes used in the intensity scales.

According to Jaeger et al. (2015), the use of short or long lists has little effect on the sensory characterization of products, but long lists may decrease the frequency of citations. In this sense, researchers should not use an excessive number of terms, instead including different terms for relevant sensory characteristics and considering consumer and product heterogeneity.

Compared with intensity scales CATA questions are a simpler and easier-to-use methodology for consumers and may have a smaller effect on hedonic scores (Adams et al., 2007). We made the same observation in the present study, where the scores for overall acceptance were higher with the CATA questions. According to Worch et al. (2010), the application of intensity scales with trained assessors and consumers provided similar results in terms of discrimination, consensus, reproducibility, and sensory maps. However, according to Ares et al. (2011a), the disadvantages of the intensity scales methodology for consumers were lack of consensus and high variability in evaluations. This was probably why the intensity scales provided more terms than the CATA questions in relation to reformulation of the products.

\section{CONCLUSIONS}

Overall, CATA questions and intensity scales allowed us to identify the sensory characteristics of Minas Frescal cheese using consumers' perceptions. According to our findings, the ideal Minas Frescal cheese should be moist and have a high intensity of white color, homogeneous mass, typical Minas Frescal cheese aroma and flavor, softness, and juiciness. Recommendations for reformulation were relatively similar for both methodologies, although we found great heterogeneity in the samples tested, a fact not previously reported in other studies, which used homogeneous samples specially manufactured for this purpose. Finally, we found that although traditional descriptive sensory profiling methods present high-quality results and are important for the dairy industry, rapid and alternative methods, such as those used in the present study, can be very useful, 


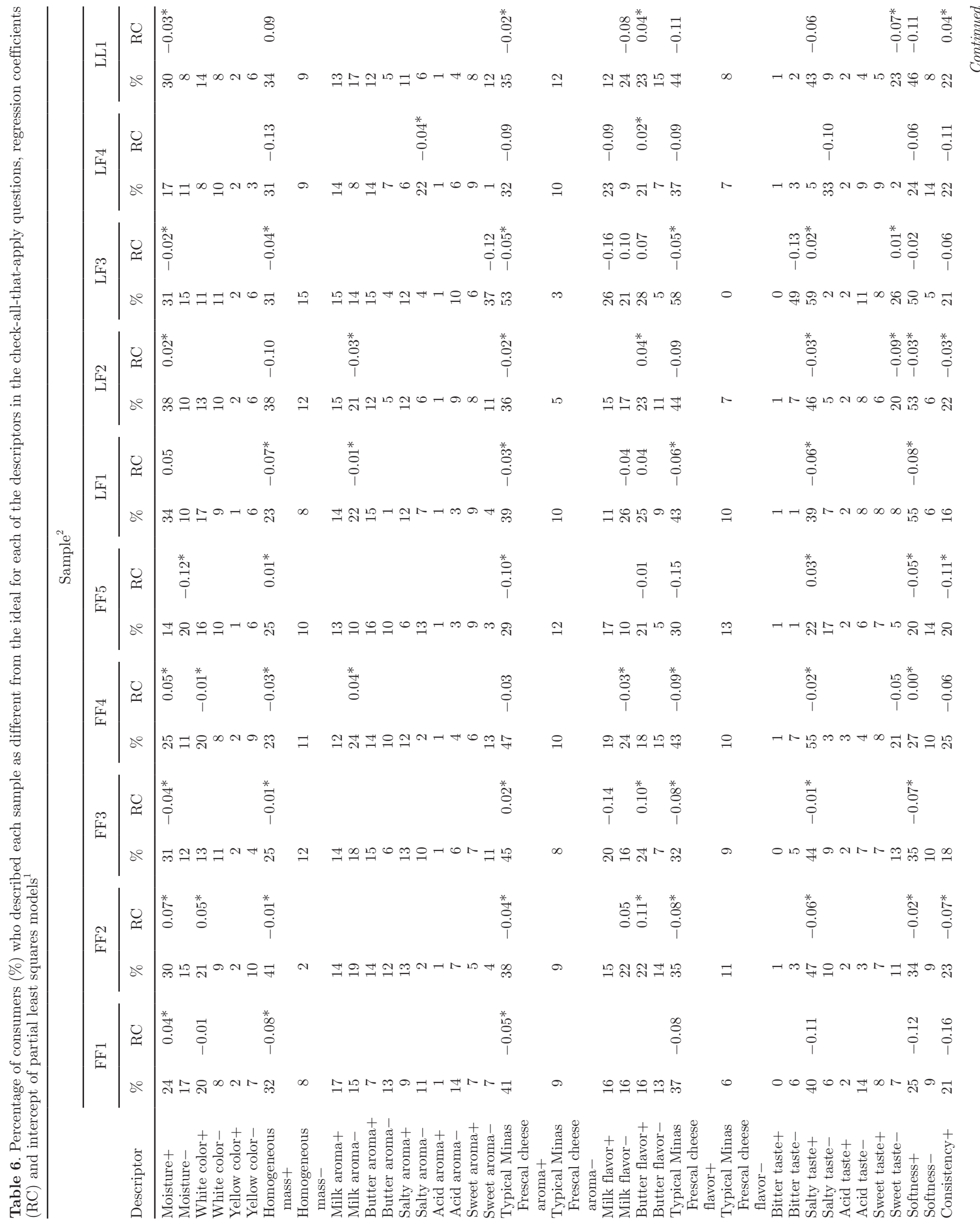


and in our context, can guide product development and reformulation of Minas Frescal cheeses more quickly and cheaply, because consumers are involved and no training steps are required.

\section{ACKNOWLEDGMENTS}

The authors are grateful for the financial support of this research provided by the National Council for Scientific and Technological Development (CNPq) and National Council for the Improvement of Higher Education (CAPES).

\section{REFERENCES}

Adams, J., A. Williams, B. Lancaster, and M. Foley. 2007. Advantages and uses of check-all-that-apply response compared to traditional scaling of attributes for salty snacks. 7th Pangborn Sensory Science Symposium, Minneapolis, MN. Elsevier, Amsterdam, the Netherlands.

Afonso, F. M., M. V. Gurgel, C. T. D. Mendes, S. R. Gregório, and M. S. Lanzilotti. 2002. Avaliação das características sensoriais em queijos Minas Frescal pasteurizado tipo tradicional e light. Hig. Aliment. 16:42-47. [In Portuguese]

Albert, A., P. Varela, A. Salvador, G. Hough, and S. Fiszman. 2011. Overcoming the issues in the sensory description of hot served food with a complex texture. Application of QDA, flash profiling and projective mapping using panels with different degrees of training. Food Qual. Prefer. 22:463-473.

Antunes, L., L. Vidal, L. Saldamando, A. Giménez, and G. Ares. 2017. Comparison of consumer-based methodologies for sensory characterization: Case study with four sample sets of powdered drinks. Food Qual. Prefer. 56:149-163

Ares, G., J. C. Andrade, L. Antúnez, F. Alcaire, M. Swaney-Stueve, S. Gordon, and S. R. Jaeger. 2017. Hedonic product optimisation: CATA questions as alternatives to JAR scales. Food Qual. Prefer. 55:67-78

Ares, G., F. Bruzzone, and A. Giménez. 2011a. Is a consumer panel able to reliably evaluate the texture of dairy desserts using unstructured intensity scales? Evaluation of global and individual performance. J. Sens. Stud. 26:363-370.

Ares, G., C. Dauber, E. Fernández, A. Giménez, and P. Varela. 2014. Penalty analysis based on CATA questions to identify drivers of liking and directions for product reformulation. Food Qual. Prefer. 32:65-76.

Ares, G., L. de Saldamando, L. Vidal, L. Antúnez, A. Giménez, and P. Varela. 2013. Polarized projective mapping: Comparison with polarized sensory positioning approaches. Food Qual. Prefer. 28:510-518.

Ares, G., R. Deliza, C. Barreiro, A. Giménez, and A. Gámbarro. 2010. Comparison of two sensory profiling techniques based on consumer perception. Food Qual. Prefer. 21:417-426.

Ares, G., P. Varela, G. Rado, and A. Gimenez. 2011b. Identifying ideal products using three different consumer profiling methodologies. Comparison with external preference mapping. Food Qual. Prefer. 22:581-591.

Bruzzone, F., G. Ares, and A. Giménez. 2012. Consumers' texture perception of milk desserts. II-Comparison with trained assessors' data. J. Texture Stud. 43:214-226.

Bruzzone, F., L. Vidal, L. Antúnez, A. Giménez, R. Deliza, and G. Ares. 2015. Comparison of intensity scales and CATA questions in new product development: Sensory characterization and directions for product reformulation of milk desserts. Food Qual. Prefer. 44:183-193.

Cowden, J., K. Moore, and K. Vanleur. 2009. Application of checkall-that-apply response to identify and optimize attributes important to consumer's Ideal product. Eighth Rose-Marie Pangborn 
Sensory Science Symposium, Florence, Italy. Elsevier, Amsterdam, the Netherlands.

Cruz, A. G., R. S. Cadena, W. F. Castro, E. A. Esmerino, J. B. Rodrigues, L. Gaze, J. A. F. Faria, M. Q. Freitas, R. Deliza, and H. M. A. Bolini. 2013. Consumer perception of probiotic yogurt: Performance of check all that apply (CATA), projective mapping, sorting and intensity scale. Food Res. Int. 54:601-610.

Dantas, A. B., V. F. Jesus, R. Silva, C. N. Almada, E. A. Esmerino, L. P. Cappato, M. C. Silva, R. S. L. Raices, R. N. Cavalcanti, C. C. Carvalho, A. S. Sant'Ana, H. M. A. Bolini, M. Q. Freitas, and A. G. Cruz. 2016. Manufacture of probiotic Minas Frescal cheese with Lactobacillus casei Zhang. J. Dairy Sci. 99:18-30.

Dooley, L., Y.-S. Lee, and J.-F. Meullenet. 2010. The application of check-all-that-apply (CATA) consumer profiling to preference mapping of vanilla ice cream and its comparison to classical external preference mapping. Food Qual. Prefer. 21:394-401.

Esmerino, E. A., J. A. Paixão, A. G. Cruz, L. Garitta, G. Hough, and H. M. A. Bolini. 2015. Survival analysis: A consumer-friendly method to estimate the optimum sucrose level in probiotic petit Suisse. J. Dairy Sci. 98:7544-7551.

Husson, F., S. Le Dien, and J. Pagès. 2001. Which value can be granted to sensory profiles given by consumers? Methodology and results. Food Qual. Prefer. 12:291-296.

Jaeger, S., D. Giacalone, C. M. Roigard, B. Pineau, L. Vidal, A. Giménez, M. B. Frost, and G. Ares. 2013. Investigation of bias of hedonic scores when co-eliciting product attribute information using CATA questions. Food Qual. Prefer. 30:242-249.

Jaeger, S. R., and G. Ares. 2014. Lack of evidence that concurrent sensory product characterization using CATA questions bias hedonic scores. Food Qual. Prefer. 35:1-5.

Jaeger, S. R., M. K. Beresford, A. G. Paisley, L. Antúnez, L. Vidal, R. S. Cadena, A. Gimenez, and G. Ares. 2015. Check-all-thatapply (CATA) questions for sensory product characterization by consumers: Investigations into the number of terms used in CATA questions. Food Qual. Prefer. 42:154-164.

Kwak, H. S., and S.-Y. Lee. 2016. Presentation methods for unidirectional scales to measure consumers' liking and disliking percepts. Food Qual. Prefer. 51:20-26.

MacFie, H. J., N. Bratchell, K. Greenhoff, and L. V. Vallis. 1989. Designs to balance the effect of order of presentation and first-order carry-over effects in hall tests. J. Sens. Stud. 4:129-148.

Marchi, R., N. D. Montes-Villanueva, M. R. McDaniel, and H. M. A. Bolini. 2012. Sensory profile and stability of a new ready-todrink passion fruit juice beverage with different sweetener systems. CENTRUM Catolicas Working Paper Series, n.2012-09-0016. http://vcentrum.pucp.edu.pe/investigacion/wps/CECYM_ WP2012-09-0016.html.
Meyners, M., J. C. Castura, and B. T. Carr. 2013. Existing and new approaches for the analysis of CATA data. Food Qual. Prefer. 30:309-319

Moskowitz, H. R. 1983. Product Testing and Sensory Evaluation of Foods. Food and Nutrition Press, Westport, CT.

Moskowitz, H. R. 1996. Experts versus consumers: A comparison. J. Sens. Stud. 11:19-37.

Moskowitz, H. R. 2001. Sensory directionals for pizza: A deeper analysis. J. Sens. Stud. 16:583-600.

Moskowitz, H. R., and J. Hartmann. 2008. Consumer research: Creating a solid base for innovative strategies. Trends Food Sci. Technol. 19:581-589.

Plaehn, D. 2012. CATA penalty/reward. Food Qual. Prefer. 24:141152.

Popper, R., W. Rosentock, M. Schraidt, and B. J. Kroll. 2004. The effect of attribute questions on overall liking ratings. Food Qual. Prefer. 15:853-858

Robert, P., and Y. Escoufier. 1976. A unifying tool for linear multivariate statistical methods: The RV coefficient. Appl. Stat. 25:257-265.

Santos, B. A., P. C. B. Campagnol, A. G. Cruz, M. T. E. L. Galvão, R. A. Monteiro, R. Wagner, and M. A. R. Pollonio. 2015. Check all that apply and free listing to describe the sensory characteristics of low sodium dry fermented sausages: Comparison with trained panel. Food Res. Int. 76:725-734.

Tarrega, A., J. Marcano, and S. Fiszman. 2016. Yogurt viscosity and fruit pieces affect satiating capacity expectations. Food Res. Int 89:574-581.

Van Kleef, F., H. C. M. Van Trup, and P. Luning. 2006. Internal versus external preference analysis: An exploratory study on end-user evaluation. Food Qual. Prefer. 17:387-399.

Worch, T., L. Dooley, J. F. Meullenet, and P. Punter. 2010. Comparison of PLS dummy variables and fishbone method to determine optimal product characteristics from ideal profiles. Food Qual Prefer. 21:1077-1087.

Worch, T., S. Lê, P. Punter, and J. Pages. 2012. Extension of the consistency of the data obtained with the Ideal Profile Method: Would the ideal products be more liked than the tested products? Food Qual. Prefer. 26:74-80.

Worch, T., S. Lê, P. Punter, and J. Pagès. 2013. Ideal Profile Method (IPM): The ins and outs. Food Qual. Prefer. 28:45-59.

Worch, T., and P. Punter. 2015. 14-Ideal profiling as a sensory profiling technique. Pages 307-332 in Rapid Sensory Profiling Techniques and Related Methods. Woodhead Publishing Series, Cambridge, UK

Xiong, R., and J. F. Meullenet. 2006. A PLS dummy variable approach to assess the impact of JAR attributes on liking. Food Qual. Prefer. 17:188-198. 